\title{
Role of apoptosis repressor with caspase recruitment domain (ARC) in cancer (Review)
}

\author{
ZHONGJIE YU ${ }^{1,2}$, QI LI $^{3}$, YI AN ${ }^{4}$, XIATIAN CHEN ${ }^{1}$, ZIQIAN LIU $^{1}$, ZHE LI $^{1}$, \\ JINNING GAO ${ }^{1}$, LYNN HTET HTET AUNG ${ }^{1}$ and PEIFENG LI ${ }^{1}$ \\ ${ }^{1}$ Center for Molecular Genetics, Institute for Translational Medicine; ${ }^{2}$ School of Basic Medicine; \\ Departments of ${ }^{3}$ Emergency Medicine and ${ }^{4}$ Cardiology, The Affiliated Hospital of Qingdao University, \\ Qingdao University, Qingdao, Shandong 266000, P.R. China
}

Received March 7, 2019; Accepted September 11, 2019

DOI: $10.3892 / \mathrm{ol} .2019 .10981$

\begin{abstract}
Apoptosis repressor with caspase recruitment domain (ARC) is a potent inhibitor of apoptosis. Under physiological conditions, ARC is abundantly expressed in terminally differentiated cells, including cardiomyocytes, skeletal muscles and neurons. ARC serves a key role in determining cell fate, and abnormal ARC expression has been demonstrated to be associated with abnormal cell growth Previous studies have revealed that ARC was upregulated in several different types of solid tumor, where it suppressed tumor cell apoptosis. Furthermore, the increased expression levels of ARC in cancer cells contributed to the development of therapeutic resistance and adverse clinical outcomes in patients with leukemia. However, the exact role of ARC, as well as the underlying molecular mechanisms involved, remain poorly understood. The present review summarizes the characteristics of ARC and its cytoprotective role under
\end{abstract}

Correspondence to: Dr Lynn Htet Htet Aung or Dr Peifeng $\mathrm{Li}$, Center for Molecular Genetics, Institute for Translational Medicine, Qingdao University, 38 Dengzhou Road, Qingdao, Shandong 266000, P.R. China

E-mail: lynnaung@qdu.edu.cn

E-mail: peifli@qdu.edu.cn

Abbreviations: ARC, apoptosis repressor with caspase recruitment domain; NOL3, Nucleolar protein 3; Fas, Fas cell surface death receptor; FADD, Fas-associated with death domain protein; DISC, death-inducing signaling complex; CK2, casein kinase 2; Kv, Voltage-gated $\mathrm{K}(+)$; $\mathrm{I}_{\mathrm{K}(\mathrm{V})}$, whole cell $\mathrm{K}_{\mathrm{v}}$ currents; PUMA, p53-upregulated modulator of apoptosis; Drp1, dynamin-related protein 1; JNK, JunN-terminal kinase; p53, protein 53 or tumor protein 53; Bax, BCL2 associated X apoptosis regulator; FOXO3A, Fork head box O3; TNF- $\alpha$, tumor necrosis factor $\alpha$; Ras, rat sarcoma; I/R, Ischemia/Reperfusion; SNX13, sorting nexin 13; CARD, caspase recruitment domain; P/E, Proline/Glutamate; AML, acute myeloid leukemia; DOX, doxorubicin; ER, endoplasmic reticulum

Key words: apoptosis repressor with caspase recruitment domain, apoptosis, cancer, cytoprotection, target therapy different conditions and describes the potential ARC as a new target for cancer therapy.

\section{Contents}

1. Introduction

2. Molecular characteristics of ARC

3. Tissue-specific expression and physiological functions of ARC in normal organs

4. Role of ARC in cancer

5. Molecular regulation of ARC expression

6. Cytoprotection and anti-apoptosis mechanisms of ARC

7. ARC will be a new target cancer therapy

8. Conclusion

\section{Introduction}

Apoptosis is a physiological form of programmed cell death (1) and is characterized by cell contraction, DNA fragmentation and the apoptotic body formation. Apoptosis is involved in the regulation of the biological processes that serve important roles in tissue development, homeostasis and disease (2). Numerous studies have demonstrated that dysregulation of apoptosis is associated with the development of several diseases, including neurological disorders (3), cardiovascular diseases (4), autoimmune diseases (5) and cancer, including colon cancer (6) and lymphoma (1). It has been reported that apoptosis is increased during hypertrophy and myocardial infarction (7). By contrast, decreased activation of apoptosis is associated with several different types of cancer, such as lung cancer (8) and breast cancer (9).

Apoptosis is a complex process that is regulated by the interaction between pro- and anti-apoptotic proteins. It has been revealed that the upregulation of anti-apoptotic proteins prevents apoptosis and allows the proliferation of cancer cells $(6,8)$.

Apoptosis repressor with caspase recruitment domain (ARC), an endogenous anti-apoptotic protein, is abundantly expressed in terminally differentiated cells such as neurons, and cardiomyocytes (10). However, previous studies have reported that ARC is upregulated in several different types of human cancer and promotes tumor cell survival, and 
contributes to tumor invasion, metastasis and chemoresistance $(9,11)$. The present review summarizes the function of ARC with a particular emphasis on the role of ARC in cancer.

\section{Molecular characteristics of ARC}

The human ARC was identified and characterized by Koseki et al (10). ARC is encoded by the nucleolar protein 3 (NOL3, also kown as NOP30) gene, which is located on chromosome 16 (12) (Fig. 1A). The coding region between exon 2 and 4 is translated to yield a peptide containing 208 amino acids with a relative molecular mass of $22,629 \mathrm{Da}(10,12)$. The 208 amino acids peptide comprises two characteristic domains; the caspase activation and recruitment and the $\mathrm{C}$-terminal domains, which are rich in proline and glutamic acid (Fig. 1B). In 2015, Jang et al published the crystal structure of the caspase recruitment domain (CARD) at a resolution of $2.4 \AA$, and revealed that it contains 95 amino acids. The dimer structure consists of five-helix bundle, which may be required for its anti-apoptotic function (13). The CARD belongs to the death domain superfamily (14), which interacts with pro-apoptotic proteins such as caspase-8, caspase-2 (10), p53-upregulated modulator of apoptosis (PUMA) (11) and BCL2 associated X apoptosis regulator (Bax) (15). The C-terminal domain consists of 113 amino acids, which is responsible for binding $\mathrm{Ca}^{2+}$ (16), and tumor protein p53 (17), thereby suppressing apoptosis.

\section{Tissue-specific expression and physiological functions of ARC in normal organs}

The expression of ARC mRNA was initially identified in human tissues by Koseki et al (10) and it was revealed that ARC is primarily expressed in skeletal muscle and the heart, but not in other tissues such as the placenta, liver or kidney. In addition, other studies have reported that ARC is expressed in the brain (18), vascular smooth muscle (19), primary spermatocytes (20), granulosa cells (21), islet $\beta$-cells (22) and cochlear hair cells (23).

Anti-apoptotic effect of ARC. ARC serves a protective role against cellular stress and is involved in homeostasis and development $(24,25)$. In a rabbit model of cardiac regional ischemia following reperfusion, rabbits overexpressing ARC exhibited decreased apoptosis in the left ventricle (24). In a murine pulmonary hypertension model, the vascular remodeling capacity of ARC-deficient mice was diminished and accompanied by enhanced apoptosis and decreased proliferation in response to chronic hypoxia-induced pulmonary hypertension (25). In chick embryo myocardial cardiomyocytes, ARC overexpression protected cells from oxidative injury and promoted their survival (26). H9c2 cells overexpressing ARC were significantly more resistant to hypoxia-induced apoptosis (27). In addition, enforced ARC overexpression significantly prevented doxorubicin (DOX)-induced cardiotoxicity (28). Overexpression of ARC remarkably suppressed whole cell $\mathrm{K}_{\mathrm{v}}$ currents $\left(\mathrm{I}_{\mathrm{K}(\mathrm{V})}\right)$ in transfected H9c2 cells following treatment with staurosporine, an apoptosis inducer that increased $\mathrm{I}_{\mathrm{K}(\mathrm{V})}$ in wild-type cells and induced apoptosis (29). These data suggest that ARC protects myocardial cells from stress-induced apoptosis as well as chemical toxicity.
In the liver, ARC overexpression completely blocked the hepatocyte apoptosis or necrosis regulated via the Fas cell surface death receptor (Fas)/tumor necrosis factor (TNF) signaling pathway $(30,31)$. Furthermore, ARC overexpression protected muscle fibers from apoptosis induced by mechanical stress or oxidative damage (32). Inhibition of ARC promoted cell death by increasing the production of pro-apoptotic factors, decreasing the stability of mitochondrial membranes and increasing the level of reactive oxygen species (ROS) following neomycin injury (23).

ARC prevented $\beta$-cell apoptosis induced by several cell death inducers, including endoplasmic reticulum (ER) stress and palmitate, while depletion of ARC in isolated islets significantly increased apoptosis in palmitate-treated cells (22). ARC expression was previously documented in testicular tissue, regulating apoptosis of primary spermatocytes (20). It was reported that ARC antagonized the adverse effect of zoldronate in osteoblasts, promoted osteogenic growth and differentiation of osteoblasts, and decreased apoptosis (33).

Other functions of ARC. In addition to its antiapoptotic role, ARC participates in the regulation of cell differentiation and proliferation. Overexpression of ARC suppressed myogenic differentiation via caspase inhibition (34), whereas the absence of ARC altered fiber-type distribution, resulting in muscle atrophy and decreased force-generating capacity (35). Russell et al (36) demonstrated that mutations, which alter the post-translational modification of ARC, may lead to myoclonus.

\section{Role of ARC in cancer}

High levels of ARC expression have previously been reported in several different types of cancer, including primary human breast cancer, cervical carcinoma, gastric cancer and colon adenocarcinoma (14,37-39). Furthermore, the expression levels were not only associated with different types of cancer, but also with sex, age, and tumor grade and size (37). Additional reports revealed that ARC is highly expressed in non-small cell lung cancer cells, $\mathrm{PC}-3$ prostate cancer cells and renal cell carcinoma cells (40-42).

ARC-induced chemoresistance. ARC expression in cancer cells has been associated with increased chemoresistance. High expression levels of ARC in breast cancer cells promoted tumor growth, invasion and metastasis, and augmented chemoresistance $(9,43)$. A high expression level of ARC in colorectal cancer liver metastasis enhanced the anti-apoptotic ability of colorectal cancer (37). ARC is highly expressed in newly diagnosed acute myeloid leukemia (AML) samples and has been demonstrated to decrease apoptosis induced by cytarabine and other agents. ARC may therefore contribute to drug resistance and increase survival time of leukemia cells (44-46). The high expression of cytoplasmic and nuclear ARC in nasopharyngeal carcinoma tissues are correlated with advanced local invasion. Overexpression of ARC in NPC 6-10B cells plays an important role in X-radiation and cisplatin resistance, and prolongs NPC cells survival by blocking the activation of casapse-8 and casapse-2 (47).

Chen et al (48) revealed that Me1007 cells overexpressing ARC inhibited caspase- 8 activation, while another study indicated that ER stress-induced apoptosis (49). Carter et al (50) 
transplanted ARC-knockdown AML cells into mice and demonstrated a significantly lower leukemia burden, increased survival rate and enhanced sensitivity to chemotherapy compared with controls. Conversely, ARC upregulated prostaglandin $\mathrm{E} 2 / \beta$-catenin production in the tumor microenvironment and augmented chemoresistance in AML cells (50). Huang et al (51) reported that increased ARC expression levels inhibited apoptosis in colon cancer. The aforementioned studies demonstrated that ARC serves an important role in the survival of cancer cells and chemotherapy resistance.

\section{Molecular regulation of ARC expression}

The expression level of ARC in tissues and cells is regulated by a number of factors, including post-transcriptional splicing, modification and degradation $(43,52,53)$.

Upregulation of ARC expression. Rat sarcoma (Ras) controls ARC levels by transcriptional regulation and maintaining protein stability. Ras activates the Nol3 promoter in a MEK/ERK-dependent manner and significantly increases the production of ARC mRNA. Furthermore, Ras prevents ARC degradation via the ubiquitin-proteasome pathway (43). The transcription factor fork head box $\mathrm{O} 3$ (FOXO3A) expressed in cardiomyocytes and skeletal muscle cells activates ARC expression by directly binding and trans-activating its promoter (52). ARC protein levels in muscle are increased as a result of endurance training; exercise resulted in a $37.5 \%$ increase in ARC protein levels (53) (Fig. 2).

Downregulation of ARC expression. Death signals induced by hypoxia $(27,54)$, ischemia-reperfusion (I/R) $(14,55)$, and other forms of stress $(14,55-57)$ have been revealed to significantly decrease ARC levels. ARC contains lysine residues at positions 17, 68 and 163. The decrease in ARC levels during apoptosis are mediated by the decreased stability of the ARC protein, an effect indicated to be mediated by ubiquitin-proteasomal-mediated degradation $(55,57)$. Previous studies have revealed that specific microRNAs (miRNAs/miRs) the decreased the expression level of ARC directly or indirectly $(39,58,59)$. ARC mRNA 3'-untranslated regions contain two miR-185 binding sites. miR-185 modulates ARC expression at the post-transcriptional level and negatively regulates ARC expression (39). miR-30d downregulates FOXO3A and inhibits ARC expression (58). miR-155 directly decreases the expression of FOXO3A and its downstream protein ARC, and may cause renal proptosis under ischemia/reperfusion injury conditions (59). p53 serves an important role in decreasing the expression and transcription of ARC as well as promoting ARC degradation via p53-induced ubiquitin E3 ligase $(57,60)$. A previous study revealed that oxidative stress enhanced post-transcriptional degradation of ARC via the ubiquitin-proteasome pathway (61). Sorting nexin-13 (SNX13), a potent mediator of heart failure, was revealed to directly modulate ARC stability and promote ARC degradation, thus increasing the apoptotic death of cardiomyocytes (62) (Fig. 2).

Post-translational regulation of ARC. A previous study revealed that the ARC protein had a molecular weight of $\sim 34 \mathrm{kDa}$ in human skeletal muscle and various adherent
A

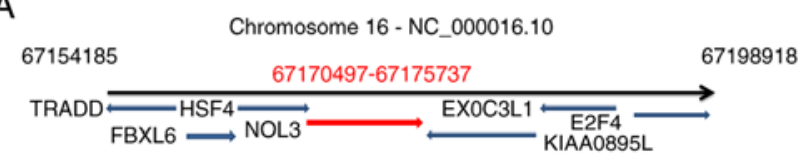

B

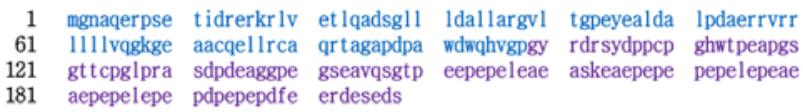

Figure 1. Coding gene location and amino acids sequences of ARC (A) The location of NOL3 coding gene on chromosome 16, highlighted in red. (B) Amino acids sequences of NOL3 coding (ARC), ARC contains two domains, CARD domain amino acids sequences (highlight with blue), $\mathrm{P} / \mathrm{E}$ domain amino acids sequences, highlighted in purple. ARC, apoptosis repressor with caspase recruitment domain; NOL3, nucleolar protein 3; CARD, caspase recruitment domain; P/E, Proline/Glutamate.



Figure 2. Regulatory factors of ARC. The factors that can either enhance ARC expression or prevent its degradation, are presented in green. The factors that can either inhibit ARC expression levels or promote its degradation, are presented in pink. The phosphorylation reaction of ARC regulated by $\mathrm{CK} 2$ are presented in lilac. ARC, apoptosis repressor with caspase recruitment domain; Ras, Rat sarcoma; FOXO3A, Fork head box O3; I/R, Ischemia/Reperfusion; SNX13, Sorting Nexin 13; p53, protein 53 or tumor protein 53; CK2, casein kinase 2; P, phosphorylation.

human cancer cell lines, and $38 \mathrm{kDa}$ in human lymphoma cell lines (63). McMillan et al (64) revealed that ARC extracted from normotensive rats had a molecular weight of $\sim 30 \mathrm{kDa}$, compared with $32 \mathrm{kDa}$ in a spontaneously hypertensive rat. This shift in molecular weight suggested that the ARC protein may undergo post-translational modifications in different and cell types. Li et al (62) reported that ARC mRNA levels did not differ between cardiac tissues extracted from rats with heart failure and controls or between SNX13-deficient neonatal rat ventricular myocytes and normal cardiomyocytes, suggesting that the regulation of ARC expression begins at the posttranscriptional level. Dowds et al (65) revealed that during the serum withdrawal stage in an in vitro culture, post-translational regulation increased ARC stability and lead to its accumulation in the nucleus, which promotes cell survival (Fig. 2). Phosphorylation is a functional post-transcriptional modification and $\mathrm{Li}$ et al (66) revealed that casein kinase 2 (CK2), is a serine/threonine protein kinase that phosphorylates ARC at threonine 149. T149 phosphorylation directs ARC to the mitochondria and allows ARC to exert its anti-apoptotic effects (Fig. 2).

\section{Cytoprotection and anti-apoptosis mechanisms of ARC}

Apoptosis is controlled by an extrinsic pathway that originates from cell-surface receptors, and an intrinsic pathway that 
involves the mitochondria and ER (1). The extrinsic pathway is mediated by death receptors (67) and death-associated domains (68). The intrinsic pathway is activated by varied stimuli, including metabolic, oxidative, proteotoxic stress and ROS (69). The extrinsic and intrinsic pathways activate caspases, which cleave multiple cellular proteins to induce cell apoptosis (70). ARC exhibits its cytoprotective and anti-apoptotic effects by inhibiting the extrinsic and intrinsic apoptotic pathways.

ARC inhibits the extrinsic apoptotic pathway. ARC inhibits the extrinsic pathway by interacting with Fas and Fas associated via the death domain. This subsequently prevents the homotypic interactions required for the assembly of the death-inducing signaling complex, which is important for the activation of caspases and further apoptotic signaling (14). A previous study revealed that ARC selectively interacts with the apoptosis initiator caspase- 2 and caspase- 8 and attenuates death receptor-induced apoptosis, involving the Fas cell surface death receptor, TNF receptor superfamily member $1 \mathrm{~A}$ and TNF receptor superfamily member 25 , or adaptor-induced apoptosis, involving TNFRSF1A associated via death domain and CASP8 and FADD like apoptosis regulator (10). Ekhterae et al (29) suggested that upregulation of ARC decreases $\mathrm{I}_{\mathrm{K}(\mathrm{V})}$ density and inhibits the staurosporine-induced $\left.I_{K(V}\right)$ increase in cardiomyocytes, thereby enhancing survival and attenuating apoptosis by inhibiting $\mathrm{K}_{\mathrm{v}}$ channel activity (29) (Fig. 3, Table I).

ARC antagonizes the intrinsic apoptotic pathway. ARC antagonizes the intrinsic pathway by interacting with apoptosis-associated proteins (11). The binding of ARC and Bax, which can inhibit Bax activation and accumulation in the mitochondria (15), increases the $\mathrm{Bcl} 2$ apoptosis regulator/Bax ratio $(71,72)$, stabilizes the mitochondrial membrane and prevents cytochrome c release $(27,73,74)$. Furthermore, ARC is also involved in the regulation of mitochondrial dynamics. For instance, ARC interacts with PUMA via its $\mathrm{N}$ terminus, and suppresses PUMA-mediated translocation of density regulated re-initiation and release factor in mitochondria, preventing mitochondrial fission and subsequent apoptosis (11).

miR-532-3p negatively regulates ARC expression and sensitizes cardiomyocytes to DOX-induced mitochondrial fission and apoptosis (75). It has been reported that ARC participates in cardioprotection and suppresses apoptosis caused by hypoxia and reoxygenation by preventing cytochrome c release from the mitochondria in a caspase-independent pattern $(27,76)$. Furthermore, ARC overexpression prevented oxidative stress-induced cell apoptosis by protecting mitochondrial function independently of caspase inhibition, suggesting that ARC may act on a mitochondrial level (56).

ARC interacts with protein kinase RNA-like ER kinase and binds inositol-requiring protein $1 \alpha$, which prevents C/EBP homologous protein induction, diminishes the ER stress response and blocks $\mathrm{Ca}^{2+}$ release from ER (22). Furthermore, ARC not only blocks $\mathrm{Ca}^{2+}$ release but also binds $\mathrm{Ca}^{2+}$ through its C-terminal P/E-rich domain. Therefore, ARC suppresses intracellular $\mathrm{Ca}^{2+}$ increase and further prevents $\mathrm{Ca}^{2+}$ mediated apoptosis (16).
The proline-glutamic acid-rich region of ARC could bind with and negatively regulate p53 by inhibiting its transcriptional function, tetramerization and causing its cytoplasmic localization, thereby preventing p53 transfer into the nucleus and abrogate p53-induced apoptosis (17).

ARC binds with and prevents the activation of JUN $\mathrm{N}$-terminal kinase (JNK), inhibiting cell death dependent on the JNK signaling pathway $(30,77,78)$. ARC blocks acetaminophen- induced hepatic damage by antagonizing the JNK signaling pathway and preventing ROS production (77). ARC decreases amyloid-induced JNK phosphorylation, and ARC upregulation decreases $\beta$-cell apoptosis induced by activation of the JNK signaling pathway (78). Furthermore, ARC blocks Fas- and TNF-regulated cell death by JNK-dependent or independent pathways (30) (Fig. 3, Table I).

ARC inhibits apoptosis induced by death receptor activation (10), oxidative stress (14), serum deprivation (27), ischemia-reperfusion (56), doxorubicin and $\gamma$-radiation (79). ARC is a potent anti-apoptotic protein that prevents permeabilization of the mitochondrial outer membrane and decreases pro-apoptotic protein release and DNA fragmentation (64).

\section{ARC will be a new target cancer therapy}

Increased ARC expression has been documented in several types of cancer cells, including colon cancers (6), lung cancer (8), leukemia (44), glioblastoma (80). ARC upregulation contributes to chemotherapy and radiation resistance $(11,81)$. Consistent with its role as an anti-apoptotic protein, ARC upregulation is associated with cancer grade and poor prognosis. For example, patients with AML with high ARC expression levels exhibited a poor chemotherapeutic response (82), while those with low ARC expression levels had an increased survival time (45), suggesting that ARC may have prognostic and therapeutic value in AML (46). ARC promotes multiple aspects of breast carcinogenesis, such as tumorigenesis, invasion, metastasis and chemoresistance. Therefore, ARC may serve as a novel therapeutic target for the development of future breast cancer therapies (9).

The antiapoptotic capacity of ARC may be regulated by certain miRNAs and enzymes. miR-185 targets ARC, decreases its anti-apoptotic function and increases apoptosis in gastric cancer cells (39). Phosphorylation of ARC by CK2 contributes to chemotherapy resistance by inhibiting DOX-induced apoptosis; whereas, CK2 inhibitors increase the sensitivity of cancer cells to DOX by inhibiting the phosphorylation of ARC (83). These data suggest that ARC can be used a novel drug target in cancer treatment (84).

In summary, ARC is an important regulator of apoptosis and is associated with several human diseases, particularly cancer. Therefore, ARC may serve as a novel drug target in cancer treatment. Furthermore, miRNAs and enzyme inhibitors may target and prevent ARC from exerting its anti-apoptotic function directly or indirectly (13).

\section{Conclusion}

Apoptosis is an important regulator of tissue and developmental homeostasis. Furthermore, apoptosis is associated with the pathogenesis of a large number of diseases, including 
Table I. ARC binding proteins and their functions mediated by binding to ARC.

Interactant

ARC-mediated function

(Refs.)

Fas/FADD

caspase-2/caspase-8

$\mathrm{K}_{\mathrm{v}}$ channel protein

PUMA

JNK

p53

$\mathrm{Ca}^{2+}$

Bax
Precludes the conventional homotypic interactions required for DISC

Attenuate apoptosis

Decreases $\mathrm{I}_{\mathrm{K}(\mathrm{V})}$ density and attenuates cardiomyocyte apoptosis

Inhibits PUMA-mediated Drp1 translocation in mitochondria and the consequent mitochondrial fission

Diminishes JNK pathway activation and apoptosis

Negatively regulate p53 by inhibiting its transcriptional function, tetramerization and triggering its cytoplasmic localization

Suppresses the intracellular $\mathrm{Ca}^{2+}$ increase and blocks $\mathrm{Ca}^{2+}$-mediated apoptosis

Prevents Bax activation and accumulations in mitochondria

ARC, apoptosis repressor with caspase recruitment domain; Fas, Fas cell surface death receptor; FADD, Fas-associated with death domain protein; DISC, death-inducing signaling complex; $\mathrm{I}_{\mathrm{K}(\mathrm{V})}$, whole cell $\mathrm{K}_{\mathrm{v}}$ currents; PUMA, p53-upregulated modulator of apoptosis; Drp1, dynamin-related protein 1; JNK, JunN-terminal kinase; p53, protein 53 or tumor protein 53; Bax, BCL2 associated X apoptosis regulator.

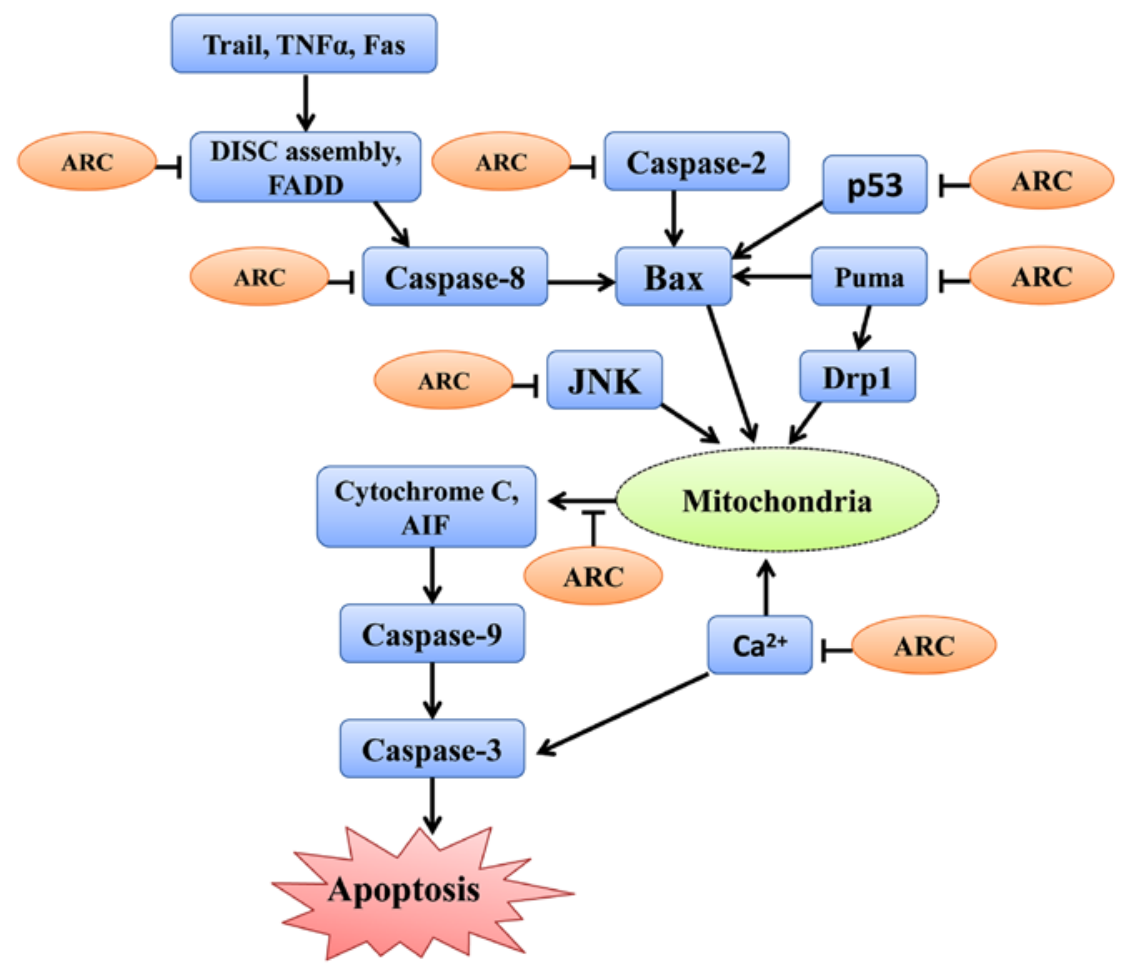

Figure 3. Roles of ARC in regulating the anti-apoptosis pathways. The pathways were simplified in the diagram. The diagram presents the key components and the reactions of apoptosis pathways that are interfered by ARC. ARC, apoptosis repressor with caspase recruitment domain; Fas, Fas cell surface death receptor; FADD, Fas-associated with death domain protein; DISC, death-inducing signaling complex; Trail, TNF-related apoptosis-inducing ligand; PUMA, p53-upregulated modulator of apoptosis; Drp1, Dynamin-related protein 1; JNK, Jun N-terminal kinase; p53, protein 53 or tumor protein 53; Bax, BCL2 associated $\mathrm{X}$ apoptosis regulator; TNF- $\alpha$, tumor necrosis factor $\alpha$; AIF, apoptosis inducing factor.

autoimmune diseases, viral infection, degenerative disorders and cancer $(85,86)$. Cancer results in significant morbidity and mortality and is a significant public health problem worldwide (87-89). The currently used chemotherapeutic drugs are cytotoxic agents that have various side effects (90). Therefore, there is a requirement for the development of targeted and more effective treatment options with fewer side effects. ARC has been revealed to decrease cell death in various different types of cell by binding and inactivating components of the apoptosis pathways. Upregulation of ARC is highly associated with tumorigenesis and chemotherapy resistance; therefore, inhibiting the expression of ARC in cancer cells may increase the efficacy of anti-cancer drugs (45). Future studies are required to investigate how to effectively deliver targeted ARC inhibitors for the treatment of cancer. 


\section{Acknowledgements}

Not applicable.

\section{Funding}

The present study was supported by the National Science Foundation of China (grant nos. 81741173 and 31430041).

\section{Availability of data and materials}

All data generated or analyzed during this study are included in this published article.

\section{Authors' contributions}

ZY, LA and PL designed the review and edited the manuscript. ZY, QL and YA wrote the manuscript. XC, ZQL, ZL and JG collected and analyzed data.

\section{Ethics approval and consent to participate}

Not applicable.

\section{Patient consent for publication}

Not applicable.

\section{Competing interests}

The authors declare that they have no competing interests.

\section{References}

1. Elmore S: Apoptosis: A review of programmed cell death. Toxicol Pathol 35: 495-516, 2007.

2. Adhihetty PJ, Ljubicic V and Hood DA: Effect of chronic contractile activity on SS and IMF mitochondrial apoptotic susceptibility in skeletal muscle. Am J Physiol Endocrinol Metab 292: E748-E755, 2007.

3. Crews L, Patrick C, Adame A, Rockenstein E and Masliah E: Modulation of aberrant CDK5 signaling rescues impaired neurogenesis in models of Alzheimer's disease. Cell Death Dis 2: e120, 2011.

4. Wang K, Long B, Zhou LY, Liu F, Zhou QY, Liu CY, Fan YY and Li PF: CARL IncRNA inhibits anoxia-induced mitochondrial fission and apoptosis in cardiomyocytes by impairing miR-539-dependent PHB2 downregulation. Nat Commun 5: 3596, 2014.

5. Qiao G, Li Z, Minto AW, Shia J, Yang L, Bao L, Tschopp J, Gao JX, Wang J, Quigg RJ and Zhang J: Altered thymic selection by overexpressing cellular FLICE inhibitory protein in T cells causes lupus-like syndrome in a BALB/c but not $\mathrm{C} 57 \mathrm{BL} / 6$ strain. Cell Death Differ 17: 522-533, 2010.

6. Rampino N, Yamamoto H, Ionov Y, Li Y, Sawai H, Reed JC and Perucho M: Somatic frameshift mutations in the BAX gene in colon cancers of the microsatellite mutator phenotype. Science 257: 967-969, 1997.

7. Mitra A, Basak T, Datta K, Naskar S, Sengupta S and Sarkar S: Role of $\alpha$-crystallin B as a regulatory switch in modulating cardiomyocyte apoptosis by mitochondria or endoplasmic reticulum during cardiac hypertrophy and myocardial infarction. Cell Death Dis 4: e582, 2013.

8. Favaloro B, Allocati N, Graziano V, Di Ilio C and De Laurenzi V: Role of apoptosis in disease. Aging (Albany NY) 4: 330-349, 2012

9. Medina-Ramirez CM, Goswami S, Smirnova T, Bamira D, Benson B, Ferrick N, Segall J, Pollard JW and Kitsis RN: Apoptosis inhibitor ARC promotes breast tumorigenesis, metastasis, and chemoresistance. Cancer Res 71: 7705-7715, 2011.
10. Koseki T, Inohara N, Chen S and Núñez G: ARC, an inhibitor of apoptosis expressed in skeletal muscle and heart that interacts selectively with caspases. Proc Natl Acad Sci USA 95: 5156-5160, 1998.

11. Wang JX, Li Q and Li PF: Apoptosis repressor with caspase recruitment domain contributes to chemotherapy resistance by abolishing mitochondrial fission mediated by dynamin-related protein-1. Cancer Res 69: 492-500, 2009.

12. Stoss O, Schwaiger FW, Cooper TA and Stamm S: Alternative splicing determines the intracellular localization of the novel nuclear protein Nop30 and its interaction with the splicing factor SRp30c. J Biol Chem 274: 10951-10962, 1999.

13. Jang TH, Kim SH, Jeong JH, Kim S, Kim YG and Park HH: Crystal structure of caspase recruiting domain (CARD) of apoptosis repressor with CARD (ARC) and its implication in inhibition of apoptosis. Sci Rep 5: 9847, 2015.

14. Nam YJ, Mani K, Ashton AW, Peng CF, Krishnamurthy B, Hayakawa Y, Lee P, Korsmeyer SJ and Kitsis RN: Inhibition of both the extrinsic and intrinsic death pathways through nonhomotypic death-fold interactions. Mol Cell 15: 901-912, 2004.

15. Gustafsson AB, Tsai JG, Logue SE, Crow MT and Gottlieb RA: Apoptosis repressor with caspase recruitment domain protects against cell death by interfering with Bax activation. J Biol Chem 279: 21233-21238, 2004.

16. Jo DG, Jun JI, Chang JW, Hong YM, Song S, Cho DH, Shim SM, Lee HJ, Cho C, Kim DH and Jung YK: Calcium binding of ARC mediates regulation of caspase 8 and cell death. Mol Cell Biol 24: 9763-9770, 2004.

17. Foo RS, Nam YJ, Ostreicher MJ, Metzl MD, Whelan RS, Peng CF, Ashton AW, Fu W, Mani K, Chin SF, et al: Regulation of p53 tetramerization and nuclear export by ARC. Proc Natl Acad Sci USA 104: 20826-20831, 2007.

18. Engidawork E, Gulesserian T, Yoo BC, Cairns N and Lubec G: Alteration of caspases and apoptosis-related proteins in brains of patients with Alzheimer's disease. Biochem Biophys Res Commun 281: 84-93, 2001.

19. Quadrilatero J and Bloemberg D: Apoptosis repressor with caspase recruitment domain is dramatically reduced in cardiac, skeletal, and vascular smooth muscle during hypertension. Biochem Biophys Res Commun 391: 1437-1442, 2010.

20. Jewgenow K, Neubauer K, Blottner S, Schön J, Wildt DE and Pukazhenthi BS: Reduced germ cell apoptosis during spermatogenesis in the teratospermic domestic cat. J Androl 30: 460-468, 2009.

21. Sasson R, Rimon E, Dantes A, Cohen T, Shinder V, Land-Bracha A and Amsterdam A: Gonadotrophin-induced gene regulation in human granulosa cells obtained from IVF patients. Modulation of steroidogenic genes, cytoskeletal genes and genes coding for apoptotic signalling and protein kinases. Mol Hum Reprod 10: 299-311, 2004.

22. McKimpson WM, Weinberger J, Czerski L, Zheng M, Crow MT, Pessin JE, Chua SC Jr and Kitsis RN: The apoptosis inhibitor ARC alleviates the ER stress response to promote $\beta$-cell survival. Diabetes 62: 183-193, 2013

23. Guan M, Fang Q, He Z, Li Y, Qian F, Qian X, Lu L, Zhang X, Liu D, Qi J, et al: Inhibition of ARC decreases the survival of HEI-OC-1 cells after neomycin damage in vitro. Oncotarget 7: 66647-66659, 2016.

24. Chatterjee S, Bish LT, Jayasankar V, Stewart AS, Woo YJ, Crow MT, Gardner TJ and Sweeney HL: Blocking the development of postischemic cardiomyopathy with viral gene transfer of the apoptosis repressor with caspase recruitment domain. J Thorac Cardiovasc Surg 125: 1461-1469, 2003.

25. Zaiman AL, Damico R, Thoms-Chesley A, Files DC, Kesari P, Johnston L, Swaim M, Mozammel S, Myers AC, Halushka M, et al: A critical role for the protein apoptosis repressor with caspase recruitment domain in hypoxia-induced pulmonary hypertension. Circulation 124: 2533-2542, 2011.

26. Wu L, Xi Z, Guo R, Liu S, Yang S, Liu D, Dong S and Guo D: Exogenous ARC down-regulates caspase-3 expression and inhibits apoptosis of broiler chicken cardiomyocytes exposed to hydrogen peroxide. Avian Pathol 42: 32-37, 2013.

27. Ekhterae D, Lin Z, Lundberg MS, Crow MT, Brosius FC III and Núñez G: ARC inhibits cytochrome c release from mitochondria and protects against hypoxia-induced apoptosis in heart-derived H9c2 cells. Circ Res 85: e70-e77, 1999.

28. An J, Li P, Li J, Dietz R and Donath S: ARC is a critical cardiomyocyte survival switch in doxorubicin cardiotoxicity. J Mol Med (Berl) 87: 401-410, 2009. 
29. Ekhterae D, Platoshyn O, Zhang S, Remillard CV and Yuan JX: Apoptosis repressor with caspase domain inhibits cardiomyocyte apoptosis by reducing $\mathrm{K}+$ currents. Am J Physiol Cell Physiol 284: C1405-C1410, 2003.

30. An J, Harms C, Lättig-Tünnemann G, Sellge G, Mandić AD Malato Y, Heuser A, Endres M, Trautwein C and Donath S: TAT-apoptosis repressor with caspase recruitment domain protein transduction rescues mice from fulminant liver failure. Hepatology 56: 715-726, 2012.

31. Kung G, Dai P, Deng L and Kitsis RN: A novel role for the apoptosis inhibitor ARC in suppressing $\mathrm{TNF} \alpha$-induced regulated necrosis. Cell Death Differ 21: 634-644, 2014.

32. Abmayr S, Crawford RW and Chamberlain JS: Characterization of ARC, apoptosis repressor interacting with CARD, in normal and dystrophin-deficient skeletal muscle. Hum Mol Gene 13: 213-221, 2004

33. Hu L, Han J, Yang X, Wang Y, Pan H and Xu L: Apoptosis repressor with caspase recruitment domain enhances survival and promotes osteogenic differentiation of human osteoblast cells under Zoledronate treatment. Mol Med Rep 14: 3535-3542, 2016.

34. Hunter AL, Zhang J, Chen SC, Si X, Wong B, Ekhterae D, Luo H and Granville DJ: Apoptosis repressor with caspase recruitment domain (ARC) inhibits myogenic differentiation. FEBS Lett 581: 879-884, 2007.

35. Mitchell AS, Smith IC, Gamu D, Donath S, Tupling AR and Quadrilatero J: Functional, morphological, and apoptotic alterations in skeletal muscle of ARC deficient mice. Apoptosis 20: 310-326, 2015

36. Russell JF, Steckley JL, Coppola G, Hahn AF, Howard MA, Kornberg Z, Huang A, Mirsattari SM, Merriman B, Klein E, et al: Familial cortical myoclonus with a mutation in NOL3. Ann Neurol 72: 175-183, 2012.

37. Tóth C, Meinrath J, Herpel E, Derix J, Fries J, Buettner R, Schirmacher P and Heikaus S: Expression of the apoptosis repressor with caspase recruitment domain (ARC) in liver metastasis of colorectal cancer and its correlation with DNA mismatch repair proteins and p53. J Cancer Res Clin Oncol 142: 927-935, 2016.

38. Mercier I, Vuolo M, Jasmin JF, Medina CM, Williams M, Mariadason JM, Qian H, Xue X, Pestell RG,Lisanti MP and Kitsis RN ARC (apoptosis repressor with caspase recruitment domain) is a novel marker of human colon cancer. Cell Cycle 7: 1640-1647, 2008.

39. Li Q, Wang JX, He YQ, Feng C, Zhang XJ, Sheng JQ and Li PF: MicroRNA-185 regulates chemotherapeutic sensitivity in gastric cancer by targeting apoptosis repressor with caspase recruitment domain. Cell Death Dis 5: e1197, 2014.

40. Toth C, Funke S, Nitsche V, Liverts A, Zlachevska V, Gasis M, Wiek C, Hanenberg H, Mahotka C, Schirmacher P and Heikaus S: The role of apoptosis repressor with a CARD domain (ARC) in the therapeutic resistance of renal cell carcinoma (RCC): The crucial role of ARC in the inhibition of extrinsic and intrinsic apoptotic signalling. Cell Commun Signal 15: 16, 2017.

41. Wang Q, Li A, Wang H and Wang J: Knockdown of apoptosis repressor with caspase recruitment domain (ARC) increases the sensitivity of human glioma cell line U251MG to VM-26. Int J Clin Exp Pathol 5: 555-561, 2012.

42. Gobe GC, Ng KL, Small DM, Vesey DA, Johnson DW, Samaratunga H, Oliver K, Wood S, Barclay JL, Rajandram R, et al Decreased apoptosis repressor with caspase recruitment domain confers resistance to sunitinib in renal cell carcinoma through alternate angiogenesis pathways. Biochem Biophys Res Commun 473: 47-53, 2016.

43. Wu L, Nam YJ, Kung G, Crow MT and Kitsis RN: Induction of the apoptosis inhibitor ARC by Ras in human cancers. J Biol Chem 285: 19235-19245, 2010

44. Mak PY, Mak DH, Ruvolo V, Jacamo R, Kornblau SM, Kantarjian H, Andreeff M and Carter BZ: Apoptosis repressor with caspase recruitment domain modulates second mitochondrial-derived activator of caspases mimetic-induced cell death through BIRC2/MAP3K14 signalling in acute myeloid leukaemia. Br J Haematol 167: 376-384, 2014.

45. Carter BZ, Qiu YH, Zhang N, Coombes KR, Mak DH, Thomas DA, Ravandi F, Kantarjian HM, Koller E, Andreeff M and Kornblau SM: Expression of ARC (apoptosis repressor with caspase recruitment domain), an antiapoptotic protein, is strongly prognostic in AML. Blood 117: 780-787, 2011

46. Mak PY, Mak DH, Mu H, Shi Y, Ruvolo P, Ruvolo V, Jacamo R, Burks JK, Wei W, Huang X, et al: Apoptosis repressor with caspase recruitment domain is regulated by MAPK/PI3K and confers drug resistance and survival advantage to AML. Apoptosis 19: 698-707, 2014.
47. Wu P, Tang Y, He J, Qi L, Jiang W and Zhao S: ARC is highly expressed in nasopharyngeal carcinoma and confers $\mathrm{X}$-radiation and cisplatin resistance. Oncol Rep 30: 1807-1813, 2013.

48. Chen LH, Jiang CC, Watts R, Thorne RF, Kiejda KA, Zhang XD and Hersey P: Inhibition of endoplasmic reticulum stress-induced apoptosis of melanoma cells by the ARC protein. Cancer Res 68: 834-842, 2008.

49. Jiang CC, Lucas K, Avery-Kiejda KA, Wade M, deBock CE, Thorne RF, Allen J, Hersey P and Zhang XD: Up-regulation of Mcl-1 is critical for survival of human melanoma cells upon endoplasmic reticulum stress. Cancer Res 68: 6708-6717, 2008.

50. Carter BZ, Mak PY, Wang X, Tao W, Ruvolo V, Mak D, Mu H, Burks JK and Andreeff M: An ARC-regulated IL1 $\beta / C o x-2 / P G E 2 /$ $\beta$-catenin/ARC circuit controls leukemia-microenvironment interactions and confers drug resistance in AML. Cancer Res 79: 1165-1177, 2019.

51. Huang W, Su G, Huang X, Zou A, Wu J, Yang Y, Zhu Y, Liang S, Li D, Ma F and Guo L: Long noncoding RNA PCAT6 inhibits colon cancer cell apoptosis by regulating anti-apoptotic protein ARC expression via EZH2. Cell Cycle 18: 69-83, 2019.

52. Lu D, Liu J, Jiao J, Long B, Li Q, Tan W and Li P: Transcription factor Foxo3a prevents apoptosis by regulating calcium through the apoptosis repressor with caspase recruitment domain. J Biol Chem 288: 8491-8504, 2003

53. Kavazis AN, McClung JM, Hood DA and Powers SK: Exercise induces a cardiac mitochondrial phenotype that resists apoptotic stimuli. Am J Physiol Heart Circ Physiol 294: H928-H935, 2008.

54. Yaniv G, Shilkrut M, Lotan R, Berke G, Larisch S and Binah O: Hypoxia predisposes neonatal rat ventricular myocytes to apoptosis induced by activation of the Fas (CD95/Apo-1) receptor: Fas activation and apoptosis in hypoxic myocytes. Cardiovasc Res 54: 611-623, 2002.

55. Nam YJ, Mani K, Wu L, Peng CF, Calvert JW, Foo RS, Krishnamurthy B, Miao W, Ashton AW, Lefer DJ and Kitsis RN: The apoptosis inhibitor ARC undergoes ubiquitinproteasomal-mediated degradation in response to death stimuli: Identification of a degradation-resistant mutant. J Biol Chem 282: 5522-5528, 2007

56. Neuss M, Monticone R, Lundberg MS, Chesley AT, Fleck E and Crow MT: The apoptotic regulatory protein ARC (apoptosis repressor with caspase recruitment domain) prevents oxidant stress-mediated cell death by preserving mitochondrial function. J Biol Chem 276: 33915-33922, 2001.

57. Foo RS, Chan LK, Kitsis RN and Bennett MR: Ubiquitination and degradation of the anti-apoptotic protein ARC by MDM2. J Biol Chem 282: 5529-5535, 2007.

58. Li X, Du N, Zhang Q, Li J, Chen X, Liu X, Hu Y, Qin W, Shen N, $\mathrm{Xu}$ C, et al: MicroRNA-30d regulates cardiomyocyte pyroptosis by directly targeting foxo3a in diabetic cardiomyopathy. Cell Death Dis 5: e1479, 2014.

59. Wu H, Huang T, Ying L, Han C, Li D, Xu Y, Zhang M, Mou S and Dong Z: MiR-155 is involved in renal ischemia-reperfusion injury via direct targeting of FoxO3a and regulating renal tubular cell pyroptosis. Cell Physiol Biochem 40: 1692-1705, 2016.

60. Li YZ, Lu DY, Tan WQ, Wang JX and Li PF: p53 initiates apoptosis by transcriptionally targeting the antiapoptotic protein ARC. Mol Cell Biol 28: 564-574, 2008.

61. Loan Le TY, Mardini M, Howell VM, Funder JW, Ashton AW and Mihailidou AS: Low-dose spironolactone prevents apoptosis repressor with caspase recruitment domain degradation during myocardial infarction. Hypertension 59: 1164-1169, 2012.

62. Li J, Li C, Zhang D, Shi D, Qi M, Feng J, Yuan T, Xu X, Liang D, $\mathrm{Xu} \mathrm{L}$, et al: SNX13 reduction mediates heart failure through degradative sorting of apoptosis repressor with caspase recruitment domain. Nat Commun 5: 5177, 2014

63. Quadrilatero J and Rush JW: Evidence for a pro-apoptotic phenotype in skeletal muscle of hypertensive rats. Biochem Biophys Res Commun 368: 168-174, 2008.

64. McMillan EM, Graham DA, Rush JW and Quadrilatero J: Decreased DNA fragmentation and apoptotic signaling in soleus muscle of hypertensive rats following 6 weeks of treadmill training. J Appl Physiol (1985) 113: 1048-1057, 2012.

65. Dowds TA and Sabban EL: Endogenous and exogenous ARC in serum withdrawal mediated PC12 cell apoptosis: A new pro-apoptotic role for ARC. Cell Death Differ 8: 640-648, 2001.

66. Li PF, Li J, Müller EC, Otto A, Dietz R and von Harsdorf R Phosphorylation by protein kinase CK2: A signaling switch for the caspase-inhibiting protein ARC. Mol Cell 10: 247-258, 2002.

67. Danial NN and Korsmeyer SJ: Cell death: Critical control points. Cell 116: 205-219,2004 
68. Itoh $\mathrm{N}$ and Nagata $\mathrm{S}$ : A novel protein domain required for apoptosis. Mutational analysis of human Fas antigen. J Biol Chem 268: 10932-10937, 1993.

69. Tait SW and Green DR: Mitochondria and cell death: Outer membrane permeabilization and beyond. Nat Rev Mol Cell Biol 11: 621-632, 2010.

70. Parrish AB, Freel CD and Kornbluth S: Cellular mechanisms controlling caspase activation and function. Cold Spring Harb Perspect Biol 5, 2013.

71. Pollack $M$ and Leeuwenburgh C: Apoptosis and aging: Role of the mitochondria. J Gerontol A Biol Sci Med Sci 56: B475-B482, 2001.

72. Dirks A and Leeuwenburgh C: Apoptosis in skeletal muscle with aging. Am J Physiol Regul Integr Comp Physiol 282: R519-R527, 2002 .

73. Ha HJ and Park HH: Molecular basis for the effect of the L31F mutation on CARD function in ARC. FEBS Lett 591: 2919-2928, 2017.

74. Dirks AJ and Leeuwenburgh C: Aging and lifelong calorie restriction result in adaptations of skeletal muscle apoptosis repressor, apoptosis-inducing factor, X-linked inhibitor of apoptosis, caspase-3, and caspase-12. Free Radic Biol Med 36: 27-39, 2004.

75. Wang JX, Zhang XJ, Feng C, Sun T, Wang K, Wang Y, Zhou LY and Li PF: MicroRNA-532-3p regulates mitochondrial fission through targeting apoptosis repressor with caspase recruitment domain in doxorubicin cardiotoxicity. Cell Death Dis 6: e1677, 2015.

76. Li YZ, Liu XH, Zhu XM and Cai LR: ARC contributes to the inhibitory effect of preconditioning on cardiomyocyte apoptosis. Apoptosis 12: 1589-1595, 2007.

77. An J, Mehrhof F, Harms C, Lättig-Tünnemann G, Lee SL, Endres M, Li M, Sellge G, Mandić AD, Trautwein C and Donath S: ARC is a novel therapeutic approach against acetaminophen-induced hepatocellular necrosis. J Hepatol 58: 297-305, 2013

78. Templin AT, Samarasekera T, Meier DT, Hogan MF, Mellati M, Crow MT, Kitsis RN, Zraika S, Hull RL and Kahn SE: Apoptosis repressor with caspase recruitment domain ameliorates amyloid-induced $\beta$-cell apoptosis and JNK pathway activation. Diabetes 66: 2636-2645, 2017.

79. Donath S, Li P, Willenbockel C, Al-Saadi N, Gross V, Willnow T, Bader M, Martin U, Bauersachs J, Wollert KC, et al: Apoptosis repressor with caspase recruitment domain is required for cardioprotection in response to biomechanical and ischemic stress. Circulation 113: 1203-1212, 2006.
80. Ziegler DS, Wright RD, Kesari S, Lemieux ME, Tran MA, Jain M, Zawel L and Kung AL: Resistance of human glioblastoma multiforme cells to growth factor inhibitors is overcome by blockade of inhibitor of apoptosis proteins. J Clin Invest 118: 3109-3122, 2008.

81. Mercier I, Vuolo M, Madan R, Xue X, Levalley AJ, Ashton AW, Jasmin JF, Czaja MT, Lin EY, Armstrong RC, et al: ARC, an apoptosis suppressor limited to terminally differentiated cells, is induced in human breast cancer and confers chemo- and radiation-resistance. Cell Death Differ 12: 682-686, 2005.

82. Carter BZ, Mak PY, Chen Y, Mak DH, Mu H, Jacamo R, Ruvolo V, Arold ST, Ladbury JE, Burks JK, et al: Anti-apoptotic ARC protein confers chemoresistance by controlling leukemia-microenvironment interactions through a NFKB/IL1 $\beta$ signaling network. Oncotarget 7: 20054-20067, 2016.

83. Wang J, Feng C, He Y, Ding W, Sheng J, Arshad M, Zhang X and Li P: Phosphorylation of apoptosis repressor with caspase recruitment domain by protein kinase CK 2 contributes to chemotherapy resistance by inhibiting doxorubicin induced apoptosis. Oncotarget 6: 27700-27713, 2015.

84. Damiano JS and Reed JC: CARD proteins as therapeutic targets in cancer. Curr Drug Targets 5: 367-374, 2004.

85. Vaux DL and Strasser A: The molecular biology of apoptosis. Proc Natl Acad Sci USA 93: 2239-2244, 1996.

86. Thompson CB: Apoptosis in the pathogenesis and treatment of disease. Science 267: 1456-1462, 1995.

87. Torre LA, Bray F, Siegel RL, Ferlay J, Lortet-Tieulent J and Jemal A: Global cancer statistics, 2012. CA Cancer J Clin 65: 87-108, 2015

88. Chen W, Zheng R, Baade PD, Zhang S, Zeng H, Bray F, Jemal A, Yu XQ and He J: Cancer statistics in China, 2015. CA Cancer J Clin 66: 115-132, 2016.

89. Fidler MM, Bray F and Soerjomataram I: The global cancer burden and human development: A review. Scand J Public Health 46: 27-36, 2018.

90. Gorjánácz M: Nuclear assembly as a target for anti-cancer therapies. Nucleus 5: 47-55, 2014.

This work is licensed under a Creative Commons Attribution-NonCommercial-NoDerivatives 4.0 International (CC BY-NC-ND 4.0) License. 